\title{
Molecular characterization of Fasciola gigantica in Delhi, India and its phylogenetic relation to the species from South Asian countries
}

\author{
Kei HAYASHI ${ }^{1,2)}$, Uday K. MOHANTA ${ }^{1,2)}$, Tambireddy NEERAJA ${ }^{3)}$ and Tadashi ITAGAKI ${ }^{1,2) *}$ \\ ${ }^{1)}$ Laboratory of Veterinary Parasitology, Faculty of Agriculture, Iwate University, 3-18-8 Ueda, Morioka 020-8550, Japan \\ ${ }^{2)}$ Department of Pathogenetic Veterinary Science, United Graduate School of Veterinary Sciences, Gifu University, 1-1 Yanagido, Gifu \\ 501-1193, Japan \\ 3) Department of Aquatic Animal Health Management Sri Venkateswara Veterinary University College of Fishery Science, Muthukur 524 \\ 344 SPSR Nellore, Andhra Pradesh, India
}

(Received 10 March 2016/Accepted 24 May 2016/Published online in J-STAGE 11 June 2016)

ABSTRACT. The aim of this study was to phylogenetically analyze Fasciola gigantica ( $F$. gigantica) from mainland India and to reveal the expansion history of F. gigantica in the Indian subcontinent. We analyzed 40 Fasciola flukes that were collected from Delhi, in the Indian mainland, and identified them as F. gigantica by using nucleotide analyses of the nuclear phosphoenolpyruvate carboxykinase (pepck) and DNA polymerase delta (pold) genes. Based on the nucleotide sequence of mitochondrial NADH dehydrogenase subunit 1 (nad1) gene, the flukes had 18 haplotypes. The haplotypes were classified under haplogroup A, which is predominant in the F. gigantica of South Asia. The population genetics of haplogroup A revealed that Delhi population showed higher $\pi$ value than eastern India population. These results suggest that F. gigantica of haplogroup A might have spread from the west to the east in India along with the artificial migration of the domestic Zebu cattle, Bos indicus.

KEY WORDS: Delhi, Fasciola gigantica, India, nadl, phylogeny

doi: 10.1292/jvms.16-0126; J. Vet. Med. Sci. 78(9): 1529-1532, 2016

Fasciola hepatica (F. hepatica) and Fasciola gigantica (F. gigantica) are well-known causative agents of fasciolosis in livestock and human being [12]. F. hepatica is mainly distributed in temperate zones, whereas $F$. gigantica is present in tropical zones [20]. Both of these species contain mature spermatozoa in their seminal vesicles for fertilization [19]. In contrast, aspermic Fasciola flukes, which contain few or no spermatozoa in the seminal vesicles, have been reported in Asia [19]. These Fasciola flukes have been identified based on their spermatogenetic status and the nucleotide sequence of nuclear ribosomal internal transcribed spacer 1 (ITS1) $[1,9,14]$. However, some Fasciola flukes have shown inconsistent results in these analyses [15]. Recently, novel nuclear single copy markers, phosphoenolpyruvate carboxykinase (pepck) and DNA polymerase delta (pold) genes, have been developed for precise discrimination of $F$. hepatica, F. gigantica and aspermic Fasciola flukes through multiplex polymerase chain reaction (PCR) and/or PCR-restriction fragment length polymorphism (RFLP) methods [18].

Molecular phylogenetic analysis and elucidation of propagation route of Fasciola species are important for the epidemic prevention of fasciolosis. F. gigantica populations in Asia have been divided into three haplogroups, $\mathrm{A}, \mathrm{B}$ and $\mathrm{C}$ based on the nucleotide sequences of the mi-

*Correspondence to: Itagaki, T., Laboratory of Veterinary Parasitology, Faculty of Agriculture, Iwate University, 3-18-8 Ueda, Morioka 020-8550, Japan. e-mail: itagaki@iwate-u.ac.jp

(C)2016 The Japanese Society of Veterinary Science

This is an open-access article distributed under the terms of the Creative Commons Attribution Non-Commercial No Derivatives (by-nc-nd) License $<$ http://creativecommons.org/licenses/by-nc-nd/4.0/>. tochondrial NADH dehydrogenase subunit 1 (nad1) gene [6]. Haplogroup A is the predominant population in Nepal, Bangladesh and eastern India on the Indian subcontinent, whereas haplogroups $\mathrm{B}$ and $\mathrm{C}$ have been distributed mainly in Southeast Asia [6]. Zebu cattle, Bos indicus, which is one of the definitive hosts of Fasciola flukes in Asia, have been domesticated in the Indus Valley, in the western area of the Indian subcontinent, and then spread throughout the subcontinent [5]. From those findings, we hypothesized that F. gigantica of haplogroup A originated in the Indus Valley, and the anthropogenic movements of domesticated Zebu cattle might have been involved in the spreading of the haplogroup [6]. In order to verify this hypothesis and to reveal the expansion history of $F$. gigantica throughout the Indian subcontinent, we analyzed Fasciola flukes collected from mainland India, which occupies a majority of the Indian subcontinent, using molecular phylogenetic analysis.

A total of 40 Fasciola flukes (1-8 flukes per host) were collected from the bile ducts of 11 buffalos at slaughterhouses in Delhi, India in December 2014 (Table 1). The flukes were fixed in $70 \%$ ethanol and transported to the laboratory for further studies. Their seminal vesicles were removed under a stereomicroscope, stained with hematoxylin-carmine solution and then observed under an optical microscope to determine the existence of sperm [19].

Total DNA was extracted from each fluke with a High Pure PCR Template Preparation Kit (Roche, Mannheim, Germany) according to the manufacturer's instructions and stored at $-20^{\circ} \mathrm{C}$ until use. The flukes were identified on the basis of nuclear ITS1, pepck and pold. The ITS1 and pold were analyzed by a PCR-RFLP method. Briefly, PCR amplicons were obtained with the primer sets: ITS1-F and ITS1-R 
Table 1. The mitochondrial nadl haplotype and spermatic status in seminal vesicles of Fasciola gigantica from Delhi

\begin{tabular}{lccc}
\hline Haplotype & Accession no. & $\begin{array}{c}\text { Number of } \\
\text { flukes }\end{array}$ & $\begin{array}{c}\text { Sperm in seminal } \\
\text { vesicles }\end{array}$ \\
\hline ND1-IN1 & LC128314 & 15 & + \\
ND1-IN2 & LC128315 & 1 & + \\
ND1-IN3 & LC128316 & 1 & + \\
ND1-IN4 & LC128317 & 1 & + \\
ND1-IN5 & LC128318 & 1 & + \\
ND1-IN6 & LC128319 & 3 & + \\
ND1-IN7 & LC128320 & 3 & + \\
ND1-IN8 & LC128321 & 1 & + \\
ND1-IN9 & LC128322 & 2 & + \\
ND1-IN10 & LC128323 & 1 & + \\
ND1-IN11 & LC128324 & 2 & + \\
ND1-IN12 & LC128325 & 1 & + \\
ND1-IN12 & LC128325 & 1 & - \\
ND1-IN13 & LC128326 & 2 & + \\
ND1-IN14 & LC128327 & 1 & + \\
ND1-IN15 & LC128328 & 1 & + \\
ND1-IN16 & LC128329 & 1 & + \\
ND1-IN17 & LC128330 & 1 & + \\
ND1-IN18 & LC128751 & 1 & + \\
Total & & 40 & \\
\hline
\end{tabular}

for ITS1 [9] and Fasciola-pold-F1 and Fasciola-pold-R1 for pold [18], and were digested using restriction enzymes $R s a \mathrm{I}$ for ITS1 and AluI for pold. The fragment patterns of the amplicons were distinguished on $1.8 \%$ agarose gels. The pepck region was amplified by a multiplex PCR with the primers, Fh-pepck-F, Fg-pepck-F and Fcmn-pepck-R, and the fragment patterns were distinguished on $1.0 \%$ agarose gels [18]. The nadl fragment was amplified with the primers, Ita 10 and Ita 2 [9], and directly sequenced in both directions with Ita 10 and Ita 2 primers using a BigDye Terminator v3.1 Cycle Sequence Kit (Applied Biosystems, Foster City, CA, U.S.A.) on an ABI 3500 Genetic Analyzer (Applied Biosystems). The resulting sequences were initially assembled using ATGC ver. 6.0.3 (Genetyx Co., Tokyo, Japan), and the haplotypes were distinguished using GENETYX ver. 10 (Genetyx Co.).

The median-joining network that was inferred from the nad1 haplotypes was generated using Network 4.6.1.2 software [2]. The frequencies of the reference haplotypes were cited from our previous studies in Japan [7, 9], South Korea [10], China [16], Vietnam [11], Thailand [4], Myanmar [8], eastern India [6], Bangladesh [15] and Nepal [17]. The frequency data of 129 Fasciola flukes that were collected in China remain unpublished. For the $F$. gigantica populations belonging to haplogroup $\mathrm{A}$, haplotype diversity $(H d)$ and nucleotide diversity $(\pi)$ were calculated using DnaSP 5.1 [13].

A total of 39 Fasciola flukes held plenty of sperm in their seminal vesicles (spermic). The flukes displayed the $F$. gigantica fragment pattern (Fg) in ITS1, pepck and pold. Thus, these flukes were identified as $F$. gigantica. The remaining one fluke did not contain any sperm in the seminal vesicle (aspermic). However, the fluke also displayed Fg in ITS1, pepck and pold, and therefore, the fluke was identified as $F$. gigantica as well (Table 1). Hence, all of the Fasciola flukes analyzed in this study were identified as F. gigantica on the basis of their molecular markers [18]. No fluke displayed the hybrid fragment pattern between $F$. hepatica and $F$. gigantica $(\mathrm{Fh} / \mathrm{Fg})$, which is a recognizable characteristic of aspermic Fasciola flukes.

The partial nucleotide sequences ( $535 \mathrm{bp}$ ) of the nadl region displayed 19 substitution sites yielding 18 haplotypes, ND1-IN1 to ND1-IN18 (GenBank accession numbers: LC128314-LC128330 and LC128751) (Table 1). All of the nad1 haplotypes belonged to F. gigantica haplogroup A, which has been primarily detected on the Indian subcontinent. No haplotype was included in the haplogroup of aspermic Fasciola flukes (Fig. 1). The predominant haplotype of $F$. gigantica from Delhi was ND1-IN1, which had a nucleotide sequence identical to the haplotypes of $F$. gigantica from Nepal (Fg-ND1-N1) [16], Bangladesh (Fg-ND1-Bd9) [15], Myanmar (ND1-M15) [7], Thailand (ND1-T13) [3] and eastern India (ND1-E6) [5]. ND1-IN2 to ND1-IN18 were colony haplotypes, which had one to three nucleotide substitutions from ND1-IN1 (Fig. 1).

No aspermic Fasciola flukes were detected among the samples collected in Delhi, though aspermic Fasciola flukes have been reported in Nepal, Bangladesh and eastern India on the Indian subcontinent [6, 15, 17]. Nad1 haplotype of one aspermic fluke, which displayed Fg fragment patterns in the ITS1, pepck and pold, was also included in the F. gigantica haplogroup A, not in the haplogroup of aspermic Fasciola flukes. Therefore, the fluke is considered $F$. gigantica that may have lost spermatogenetic ability due to aging or other unknown causes. F. gigantica with no sperm in their seminal vesicles was also detected in Myanmar [8], Bangladesh [15] and eastern India [6]. Aspermic Fasciola flukes were predominant in Bangladesh (86.0\%) [15] and Nepal (75.3\%) [17], while the prevalence was low in eastern India (24.8\%) [6]. Aspermic Fasciola flukes are thought to have originated in China and have been introduced into these countries [15-17], and thus, these results suggest that the flukes have not yet dispersed extensively throughout India. However, to verify this phenomenon, further analysis of Fasciola flukes from other localities in India is required.

All of the nadl haplotypes of $F$. gigantica collected from Delhi were categorized into haplogroup A. Similarly, $F$. gigantica haplotypes from the Indian subcontinent, Nepal [17], Bangladesh [15] and eastern India [6] also belonged to haplogroup A. In contrast, the haplotypes collected from Southeast Asia, Thailand and Myanmar belonged to haplogroups $\mathrm{B}$ and $\mathrm{C}$ in addition to haplogroup $\mathrm{A}[4,8]$. Moreover, the $\pi$ value of haplogroup A was the highest in the Nepal (0.00366), followed by Bangladesh (0.00362), Delhi (0.00255), eastern India (0.00242) and Myanmar $(0.00225)$ populations (Table 2$)$. Genetic diversity in the latest population generally decreases with distance from its geographical origin $[3,5,21]$. These $\pi$ values suggest that F. gigantica populations of haplogroup A might have been spread from the west to the east in India. Additionally, zebu cattle have been domesticated in the Indus Valley and then 


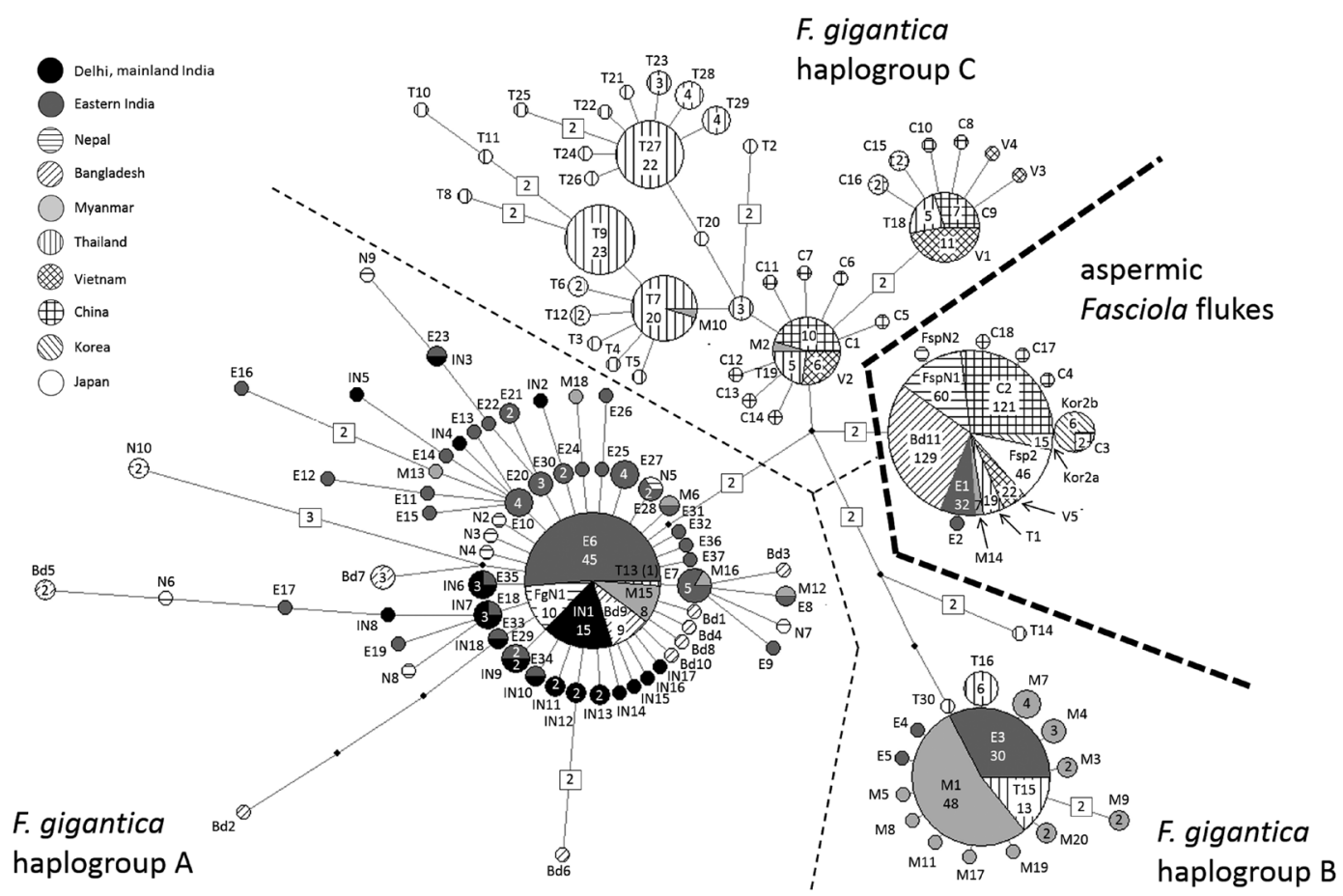

Fig. 1. A median-joining network on the basis of mitochondrial nadl haplotypes of Fasciola gigantica and aspermic Fasciola flukes. Fasciola flukes from Delhi are shown in black. A circle indicates a haplotype. Haplotype codes are labeled within or adjacent to the circles. The prefix of each haplotype code, ND1-, used in Table 1 was omitted. Numbers on each circle and node indicate the number of flukes and substitution sites, respectively. Circles and nodes without labeled numbers indicate that the number is only one. Small, dark circles on the node represent median vectors. A thick dashed line separates F. gigantica from aspermic Fasciola sp., and thin dashed lines divide the three haplogroups of $F$. gigantica.

Table 2. Diversity indices for F. gigantica populations of the haplogroup a on the basis of the sequence of mitochondrial nadl gene

\begin{tabular}{lcrrcc}
\hline \multicolumn{1}{c}{ Populations } & $\mathrm{N}$ & $\mathrm{S}$ & $\mathrm{h}$ & $\mathrm{Hd} \pm \mathrm{SD}$ & $\pi$ \\
\hline Delhi & 40 & 19 & 18 & $0.853 \pm 0.052$ & 0.00255 \\
Eastern India [6] & 91 & 32 & 32 & $0.751 \pm 0.050$ & 0.00242 \\
Nepal [18] & 20 & 16 & 10 & $0.758 \pm 0.101$ & 0.00366 \\
Bangladesh [16] & 20 & 15 & 10 & $0.832 \pm 0.075$ & 0.00362 \\
Myanmar [8] & 13 & 7 & 6 & $0.641 \pm 0.150$ & 0.00225 \\
\hline
\end{tabular}

$\mathrm{N}$ : number of flukes used for calculation, $\mathrm{S}$ : number of substitution sites, h: number of haplotypes, Hd: haplotype diversity, SD: standard deviation, $\pi$ : nucleotide diversity. Numbers in brackets represent those of the references.

spread throughout Indian subcontinent from the west to the east [5], and therefore, the F. gigantica populations in India might have spread along with the anthropogenic movement of the ruminant $[6,15,17]$. However, the $\pi$ value of the Delhi population was smaller than that of Nepal and Bangladesh, although Delhi is located in the west than the two countries. This inconsistency might be caused by using Fasciola samples collected from a single locality (Delhi) in vast mainland of India. Moreover, the number and geographical source of the flukes analyzed in this study are inadequate to confirm the hypothesis. Therefore, further phylogenetic studies using additional Fasciola flukes from mainland India are required to understand the spreading route of $F$. gigantica.

ACKNOWLEDGMENTS. This study was supported in part by the Grants-in-Aid for Science Research (B) and (C) (grant nos. 23405044 and 24580420) from the Ministry of Education, Culture, Sports, Science and Technology of Japan.

\section{REFERENCES}

1. Adlard, R. D., Barker, S. C., Blair, D. and Cribb, T. H. 1993. Comparison of the second internal transcribed spacer (ribosomal DNA) from populations and species of Fasciolidae (Digenea). Int. J. Parasitol. 23: 423-425. [Medline] [CrossRef]

2. Bandelt, H. J., Forster, P. and Röhl, A. 1999. Median-joining networks for inferring intraspecific phylogenies. Mol. Biol. Evol. 16: 37-48. [Medline] [CrossRef]

3. Beja-Pereira, A., Caramelli, D., Lalueza-Fox, C., Vernesi, C., Ferrand, N., Casoli, A., Goyache, F., Royo, L. J., Conti, S., Lari, M., Martini, A., Ouragh, L., Magid, A., Atash, A., Zsolnai, A., Boscato, P., Triantaphylidis, C., Ploumi, K., Sineo, L., Mallegni, F., Taberlet, P., Erhardt, G., Sampietro, L., Bertranpetit, J., Barbujani, G., Luikart, G. and Bertorelle, G. 2006. The origin of European cattle: evidence from modern and ancient DNA. Proc. Natl. Acad. Sci. U.S.A. 103: 8113-8118. [Medline] [CrossRef] 
4. Chaichanasak, P., Ichikawa, M., Sobhon, P. and Itagaki, T. 2012. Identification of Fasciola flukes in Thailand based on their spermatogenesis and nuclear ribosomal DNA, and their intraspecific relationships based on mitochondrial DNA. Parasitol. Int. 61: 545-549. [Medline] [CrossRef]

5. Chen, S., Lin, B. Z., Baig, M., Mitra, B., Lopes, R. J., Santos, A. M., Magee, D. A., Azevedo, M., Tarroso, P., Sasazaki, S., Ostrowski, S., Mahgoub, O., Chaudhuri, T. K., Zhang, Y. P., Costa, V., Royo, L. J., Goyache, F., Luikart, G., Boivin, N., Fuller, D. Q., Mannen, H., Bradley, D. G. and Beja-Pereira, A. 2010. Zebu cattle are an exclusive legacy of the South Asia neolithic. Mol. Biol. Evol. 27: 1-6. [Medline] [CrossRef]

6. Hayashi, K., Ichikawa-Seki, M., Mohanta, U. K., Singh, T. S., Shoriki, T., Sugiyama, H. and Itagaki, T. 2015. Molecular phylogenetic analysis of Fasciola flukes from eastern India. Parasitol. Int. 64: 334-338. [Medline] [CrossRef]

7. Ichikawa, M., Iwata, N. and Itagaki, T. 2010. DNA types of aspermic Fasciola species in Japan. J. Vet. Med. Sci. 72: 13711374. [Medline] [CrossRef]

8. Ichikawa, M., Bawn, S., Maw, N. N., Htun, L. L., Thein, M., Gyi, A., Sunn, K., Katakura, K. and Itagaki, T. 2011. Characterization of Fasciola spp. in Myanmar on the basis of spermatogenesis status and nuclear and mitochondrial DNA markers. Parasitol. Int. 60: 474-479. [Medline] [CrossRef]

9. Itagaki, T., Kikawa, M., Sakaguchi, K., Shimo, J., Terasaki, K., Shibahara, T. and Fukuda, K. 2005. Genetic characterization of parthenogenic Fasciola sp. in Japan on the basis of the sequences of ribosomal and mitochondrial DNA. Parasitology 131: 679-685. [Medline] [CrossRef]

10. Itagaki, T., Kikawa, M., Terasaki, K., Shibahara, T. and Fukuda, K. 2005. Molecular characterization of parthenogenic Fasciola sp. in Korea on the basis of DNA sequences of ribosomal ITS1 and mitochondrial NDI gene. J. Vet. Med. Sci. 67: 1115-1118. [Medline] [CrossRef]

11. Itagaki, T., Sakaguchi, K., Terasaki, K., Sasaki, O., Yoshihara, S. and Van Dung, T. 2009. Occurrence of spermic diploid and aspermic triploid forms of Fasciola in Vietnam and their molecular characterization based on nuclear and mitochondrial DNA. Parasitol. Int. 58: 81-85. [Medline] [CrossRef]

12. Keiser, J. and Utzinger, J. 2005. Emerging foodborne tremato- diasis. Emerg. Infect. Dis. 11: 1507-1514. [Medline] [CrossRef] 13. Librado, P. and Rozas, J. 2009. DnaSP v5: a software for comprehensive analysis of DNA polymorphism data. Bioinformatics 25: 1451-1452. [Medline] [CrossRef]

14. Marcilla, A., Bargues, M. D. and Mas-Coma, S. 2002. A PCRRFLP assay for the distinction between Fasciola hepatica and Fasciola gigantica. Mol. Cell. Probes 16: 327-333. [Medline] [CrossRef]

15. Mohanta, U. K., Ichikawa-Seki, M., Shoriki, T., Katakura, K. and Itagaki, T. 2014. Characteristics and molecular phylogeny of Fasciola flukes from Bangladesh, determined based on spermatogenesis and nuclear and mitochondrial DNA analyses. Parasitol. Res. 113: 2493-2501. [Medline] [CrossRef]

16. Peng, M., Ichinomiya, M., Ohtori, M., Ichikawa, M., Shibahara, T. and Itagaki, T. 2009. Molecular characterization of Fasciola hepatica, Fasciola gigantica, and aspermic Fasciola sp. in China based on nuclear and mitochondrial DNA. Parasitol. Res. 105: 809-815. [Medline] [CrossRef]

17. Shoriki, T., Ichikawa-Seki, M., Devkota, B., Rana, H. B., Devkota, S. P., Humagain, S. K. and Itagaki, T. 2014. Molecular phylogenetic identification of Fasciola flukes in Nepal. Parasitol. Int. 63: 758-762. [Medline] [CrossRef]

18. Shoriki, T., Ichikawa-Seki, M., Suganuma, K., Naito, I., Hayashi, K., Nakao, M., Aita, J., Mohanta, U. K., Inoue, N., Murakami, K. and Itagaki, T. 2016. Novel methods for the molecular discrimination of Fasciola spp. on the basis of nuclear protein-coding genes. Parasitol. Int. 65: 180-183. [Medline] [CrossRef]

19. Terasaki, K., Akahane, H., Habe, S. and Moriyama, N. 1982. The geographical distribution of common liver flukes (the genus Fasciola) with normal and abnormal spermatogenesis. Jpn. J. Vet. Sci. 44: 223-231. [Medline] [CrossRef]

20. Torgerson, P. and Claxton, J. 1999. Epidemiology and control. pp. 113-149. In: Fasciolosis. (Dalton, J. P. ed.), CABI publishing, New York.

21. Troy, C. S., MacHugh, D. E., Bailey, J. F., Magee, D. A., Loftus, R. T., Cunningham, P., Chamberlain, A. T., Sykes, B. C. and Bradley, D. G. 2001. Genetic evidence for Near-Eastern origins of European cattle. Nature 410: 1088-1091. [Medline] [CrossRef] 